\title{
Influence of land crabs Gecarcinus quadratus (Gecarcinidae) on distributions of organic carbon and roots in a Costa Rican rain forest
}

\author{
Peter M. Sherman \\ Previous Address: School of Natural Resources \& Environment, University of Michigan, Ann Arbor, MI 48109, USA. \\ Current Address: Deep Springs College, Deep Springs Valley, California, USA. Mailing address: HC 72, Box 45001, Dyer, \\ Nevada 89010 USA. psherman888@msn.com
}

Received 04-II-2005. Corrected 10-IX-2005. Accepted 03-X-2005.

\begin{abstract}
In Costa Rica's Corcovado National Park, the fossorial land crab, Gecarcinus quadratus (Gecarcinidae), densely populates $\left(1-6 \mathrm{~m}^{-2}\right)$ a region of forest extending from the Park's Pacific coastline inland to ca. $600 \mathrm{~m}$. Throughout this coastal forest ('crabzone'), crabs selectively forage for fallen leaves and relocate them to subterranean burrow chambers. Comparisons between surface soils $(0-15 \mathrm{~cm})$ sampled from the crabzone and forest lying immediately inland that is naturally devoid of crabs ('crabless zone') suggest that crabzone top soils contained less organic carbon and fewer fine and very fine roots. In contrast, soils sampled from 70 - $100 \mathrm{~cm}$ depths in the crabzone contained twice the carbon of the crabless zone during the dry season but similar values during the wet season. Two years of experimental crab exclusion from $25 \mathrm{~m}^{2}$ replicates established in the crabzone resulted in $16 \%$ more organic carbon content in surface soils relative to baseline conditions (n.s.) and $22 \%$ more carbon than final control values $(\mathrm{P}<0.05)$. Excavations of burrow chambers, with an average $( \pm \mathrm{SD})$ depth of $48 \pm 12 \mathrm{~cm}$, indicated localized, subterranean pockets of elevated $(+60 \%)$ organic carbon and increased densities of fine and very fine roots relative to same-depth samples from the crabzone unassociated with burrows chambers. Rev. Biol. Trop. 54(1): 149-161. Epub 2006 Mar 31.
\end{abstract}

Key words: Coastal, Corcovado National Park, Costa Rica, distribution, Gecarcinidae, Gecarcinus quadratus, land crab, leaf litter, neotropical rain forest, nutrient, organic carbon, plant, roots, community.

The deposition, accumulation and microbial decomposition of leaf-litter represent a major vector for nutrient return to forest soils in both tropical (Vitousek and Sanford 1986) and temperate zones (Norden 1994). Factors that alter litter dynamics potentially influence nutrient cycling processes and, thereby, plant establishment and growth (Facelli and Pickett 1991a, b; Molofsky and Augspurger 1992), primary productivity (Lugo et al. 1973), and root strategies (Haines 1978). Although community ecologists recognize that fauna represent one such factor, relatively few systems have been isolated, studied and mechanistically described (but see review of smaller invertebrates, Lavelle 1997).
While mangrove crab systems have been relatively well studied with a consensus that crabs collectively remove fallen leaves to their burrows (sensu Robertson 1986, Robertson and Daniel 1989, Emmerson and McGwynne 1992, McIvor and Smith 1995), the similarly conspicuous effects of land crabs of the family Gecarcinidae living in coastal tierre firme forests pan-tropically have attracted surprisingly little attention. To the best of my knowledge, large-scale litter removal by Gecarcinidae has been described by only a few authors (Capistran-Barradas et al., Pers. Comm. 2001) and experimentally investigated by four others (O'Dowd and Lake 1989, Kellman and Delfosse 1993, Green et al. 1999, Sherman 
2003). This small body of work contributes to our understanding that during seasons of high crab activity, surface accumulations of leaf litter can be substantially reduced by selectively foraging crabs.

The animal subject and study site: The land crab Gecarcinus quadratus de Saussure (1853; Gecarcinidae) lives in neotropical coastal rain forests. Considered by many to be synonymous with Gecarcinus lateralis (Burggren and McMahon 1988, Turkay 1973), populations of G. quadratus extend from Florida, Bermuda and the Antilles down the east coast of Central America to Guyana and down the west coast of Latin America from Mexico to Peru (Burggren and McMahon 1988). My study site is the Sirena Biological Station on the Pacific coast of Costa Rica's Corcovado National Park $\left(8^{\circ} 27^{\prime} \mathrm{N}\right.$ to $8^{\circ} 30^{\prime} \mathrm{N}$ and $83^{\circ} 25^{\prime} \mathrm{W}$ to $83^{\circ} 45^{\prime} \mathrm{W}$ ).

At my study site, Gecarcinus quadratus (Gecarcinidae) construct single-occupancy burrows that can extend $1.5 \mathrm{~m}$ long to depths of over $1 \mathrm{~m}$. Although crabs frequently exchange burrows, preliminary data suggest that burrows can remain actively occupied for more than 1 year (Sherman 1997). Active primarily during the wet season that extends from April through December, G. quadratus emerge nocturnally from their burrows and forage for fruits, seeds, seedlings (Sherman 2002) and leaf litter (Sherman 2003). It is possible that by relocating a majority of the leaf litter layer from the soil surface to their subterranean chambers (Sherman 2003), land crabs may facilitate, over months or years, the movement of nutrients to deeper soils where roots may subsequently forage. Given that crab densities routinely exceed one adult $\mathrm{m}^{-2}$ in the coastal forest of Corcovado, the overall effect of such population-wide litter relocation from surface to burrow chamber may be detectable and biologically significant.

Such litter relocation is visually conspicuous and two adjacent, but contrasting, zones can thereby be described: The "crabzone" extends from the forest/beach interface to approximately $600 \mathrm{~m}$ inland where it transitions over approximately $30 \mathrm{~m}$ into the remaining inland forest that I term the"crabless zone". This region, although adjacent with the crabzone, is devoid of crabs and accumulates year-round a thick layer of leaf litter and decomposing humus $(>15 \mathrm{~cm})$ on the soil surface. Fungal hyphae and a diverse decomposer community are continuously active in this litter layer. The two zones can also be described by two different soil regimes with the coastal crabzone categorized as sandy-loam relative to the inland crabless zone's clays. This important difference in substrates, and its potential influence on both crab ecology and nutrient dynamics, is beyond the scope of this current study and represents the next phases of research. For further details on the study subject or location see Sherman (1997, 2002, 2003).

For this paper, I use sampling and experimentation to investigate whether litter relocation by $G$. quadratus affects distributions of soil organic carbon and root distributions. For my descriptive sampling efforts, I asked the following questions: (a). Are concentrations of organic carbon in top-soils $(<15 \mathrm{~cm})$ lower in the crabzone than adjacent crabless zone? (b). Are organic carbon concentrations in deeper soils (32 and $72 \mathrm{~cm}$ ) higher in crabzone soils than nearby crabless zone soils? (c). Within the crabzone, do concentrations of organic carbon in surface soils decrease with distance from the crab burrow entrances? (d). Within the crabzone, does the relocation of leaf litter from soil surface to burrow chambers, by crabs, result in a continuous layer of elevated carbon or, rather, isolated pockets of increased carbon concentration in the soils surrounding chambers relative to same-depth crabzone soils specifically unassociated with burrows? (e). Will root densities be higher in those areas where organic carbon is hypothesized to be relatively higher (crabless zone surface soils, crabzone deeper soils and burrow chambers), than other nearby soils? In an attempt to provide a more explanatory, mechanistic connection between land crabs, leaf litter, carbon and root distributions, I also created areas of expimental crab exclusion within the crabzone over a two-y period. Using 
these exclosures, I asked the following questions: (f). Does the experimental exclusion of land crabs from replicated regions within the forested crabzone, after two y, result in organic carbon concentrations that are (i) elevated in the topsoil and (ii) reduced at lower depths (32 and $72 \mathrm{~cm}$ ) relative to control regions?

\section{MATERIALS AND METHODS}

Organic Carbon Distribution: To compare patterns of organic carbon distributions between the two adjacent forested zones (crab and crabless), I collected soil profiles from three depths with a tube sampler (bore $=1.91 \mathrm{~cm} \mathrm{x}$ $22.9 \mathrm{~cm}$ ). These three depths, (surface: 0-15 cm), 32 and $72 \mathrm{~cm}$ ) used throughout the study, were chosen as to straddle the average burrow chamber depth $(50 \mathrm{~cm})$ determined through pilot work. Sites within the crabless zone (CLZ) were haphazardly chosen within $<100$ m inland from of the border with the crabzone (CZ). CZ samples were collected from within replicated $25 \mathrm{~m}^{2}$ quadrangles associated with a randomized block experimental design described below (sampled exclusively from control quadrangles). Soil profiles were collected during the wet and dry seasons from both zones and all comparisons described are seasonally-specific. Samples sizes for zonal comparisons are described in the legend of Table 1 .

Within the CZ, I additionally sampled soils for organic carbon analysis from crab burrow entrances, piles of burrow excavate and burrow chambers. Crab faecal pellets were also collected from excavate. To estimate if burrowing activities influenced concentrations of organic carbon of soils surrounding burrow entrances, I sampled surface soils from around five burrow entrances in the four cardinal directions at concentric distances of 10, 25, 40, 55 and $70 \mathrm{~cm}$. To determine if by burrowing, crabs created isolated pockets of elevated carbon at their chambers, I collected soils from 12 excavated chambers and made depth-specific comparisons to $\mathrm{CZ}$ soils experimentally disassociated from burrows. To accomplish this, I created five crab exclosures within the $\mathrm{CZ}$ (described in further detail below). From each of five spatiallyseparated exclosures I collected two profiles over three sampling periods for a total of 30 samples collected for each of three pre-selected depths. From these averages, I predicted carbon content at the specific depths for each chamber using a linear regression equation.

All soil and faecal samples were air-or oven-dried (40 degrees C) on site within one $\mathrm{d}$ of collection and transported, within two mos, in air-tight bags, to the University of Michigan Soils Laboratory for analysis. I estimated percent organic carbon content using a wet-combustion method where soil organic carbon is oxidized through exposure to sulfuric acid and potassium dichromate (Allison 1965).

Root Profiles: I sampled root densities from the two zones and in soils surrounding burrow chambers. From the two zones, I measured root densities to depths of one $m$ after excavating 11 pits in the $\mathrm{CZ}$ and 4 pits in the CLZ. Within each zone, I selected pit locations haphazardly based upon relative ease of digging (avoiding major tree trunks and roots) and a localized absence of crab burrows. Within each pit, I randomly located a 5-cm wide vertical transect from the surface down along which I counted all exposed roots categorizing them into very fine $=<1 \mathrm{~mm}$ and fine $=1-5 \mathrm{~mm}$ diameters. From 15 burrows excavated during the rainy season, I counted very fine and fine root densities associated with burrow chambers. I also counted roots vertically above the chambers using vertical transects as described for pits. Additionally, I compared root densities (fine and very fine root densities combined) of chambers to depth-specific average root density values obtained (in $5 \mathrm{~cm}$ increments) from the 11 pits excavated pits in the $\mathrm{CZ}$ (same region, no burrows).

Crab Exclusion Experiment: To investigate the mechanism by which land crabs may affect organic carbon and root distributions, I excluded crabs from forested regions within the $\mathrm{CZ}$ for two y using a randomized block design. 
I collected baseline data in July 1994 and final samples in July 1996 and interim samples during October 1995 and January 1996. I organized fifteen 5 x 5 m quadrangles into five spatially-separated triplets (blocks). The three quadrangles of each replicate block were randomly assigned to one of three treatments: a). "fenced-exclosure"(experimental treatment), b). "fenced-control"or c). "open control". A $0.5-\mathrm{m}$ high wire fence (mesh $2.5 \mathrm{~cm} \times 1.25$ $\mathrm{cm})$ that restricted most fauna larger than the mesh from entering surrounded fenced-exclosure and fenced-control quadrangles. Fencedcontrol quadrangles had holes $(20 \times 20 \mathrm{~cm})$ cut every $60 \mathrm{~cm}$ into the fencing permitting crab access but not larger fauna. From this same design, I determined that crab exclusion results in significant accumulations of leaf litter on the soil surface (Sherman 2003). Therefore, within each $25-\mathrm{m}^{2}$ quadrangle, I also repeatedly collected two soil profiles from randomly-chosen one- $\mathrm{m}^{2}$ plots over two $\mathrm{y}$. Using the soil tube sampler described above, I extracted soil cores of $2 \times 23 \mathrm{~cm}$ from the three pre-determined depths rationalized above (surface, $32 \mathrm{~cm}$ and $72 \mathrm{~cm}$ ). For further design details, see Sherman (1997, 2002 or 2003).

Statistical analysis: Depth-specific comparisons between chambers and near-by soils of both organic carbon content (regression from 30 profiles) and root densities (11 excavated pits) were made using paired-samples t-tests. Comparisons of root profiles between the craband crabless zones were made using independent sample t-tests. For all t-tests performed, separate variance probabilities were used where unequal variances were found; otherwise, pooled variance probabilities were used.

I analyzed the randomized-block (crab exclusion) experiment with simple and repeated-measures ANOVA. Analyses were performed seperately for each of the three soil depths sampled (surface, $32 \mathrm{~cm}$ and $72 \mathrm{~cm}$ ). Baseline (July 1994) and final sampling period (July 1996) data were analyzed individually to clarify patterns before and after treatment. A Bonferroni adjustment was used with these two
ANOVAs per soil depth sampled and statistical significance reduced to alpha $=0.025$. The two-way ANOVAs tested the factors treatment (fenced-exclosure, fenced-control and opencontrol), spatial block, and the treatment $\mathrm{x}$ block interaction (residual error term).

To assess the influence of time (two y) of crab exclusions on changing soil organic carbon content in this experimental replicates, I analyzed the data using a two-way repeated measures ANOVA from soils sampled from the three depths. Treatment and spatial-block were the two between-subjects factors, time was the within-subjects repeated measure (October 1995, January 1996, July 1996). Baseline data were excluded from repeatedmeasures analysis except to check separately for significant covariance.

I present the output from two models of the repeated-measures in ANOVA in response to the long history of polarization among statisticians regarding how experiments are to be analyzed when the blocking factors are neither stictly random nor fixed as is the case here (Newman et al. 1997). I follow the authors' suggestion and present two analyses that differ in their assumptions, risks of pseudoreplication, choice of residual error and null hypotheses tested. Model I is the conventional ANOVA output (General Linear Model, SYSTAT v9 for Windows, SPSS 1998) assumes that the blocks are randomly selected from a larger population of blocks and recognizes blocking variable interactions. This Model, therefore, uses the mean squares of the treatment $\mathrm{x}$ block interaction as the error term for the betweensubjects analysis is the time $\mathrm{x}$ treatment $\mathrm{x}$ block interaction as the error for the within-subjects analysis. Model I tests the null hypothesis that although treatment effects may exist for individual blocks, they average out to zero over all blocks. Although it is plausible that my spatial blocks sample the forest as a whole, strictly speaking, I established them more haphazardly than warranted by a purely random selection. Therefore, Model II ANOVA is used because it does not assume that blocks are random samples from a population of blocks 
such that treatment $\mathrm{x}$ block interactions are unlikely. The error term for both between-and within-subjects analyses is the pooled mean square of the treatment $\mathrm{x}$ block, time $\mathrm{x}$ block and time $\mathrm{x}$ treatment $\mathrm{x}$ block interactions and is used to test for treatment, time, and the time $\mathrm{x}$ treatment interaction. Model II tests the null hypothesis that treatment effects, do not exist for any of the blocks. Although I tend towards the more cautious model II, I present both analyses so that the readership can interpret the data as it sees fit.

The residuals from the repeated measures ANOVA models, and all other parametric analyses, were examined for serious departures from normality and homogeneity of variance. Alpha was set to 0.05 and two-tailed probabilities were used for all analyses unless stated. All expressions of variation are standard errors unless specified as standard deviations.

\section{RESULTS}

\section{Organic carbon profiles and soil content:}

Percent organic carbon in the crabzone $(\mathrm{CZ})$ soils decreased with depth $(y=1.76-0.016 x$; $r^{2}>0.99 ; n=90$ samples; $n=30$ per depth). Carbon concentrations at the soil surface were $1.8 \pm 0.05 \%(\min =1.0 \%, \max =3.9 \%) ; 32 \mathrm{~cm}$ were $1.2 \pm 0.03 \%(\min =0.6 \%, \max =2.4 \%)$; and $72 \mathrm{~cm}$ were $0.6 \pm 0.05 \%(\min =0.1 \%$, max $=1.5 \%$ ). Crabless zone (CLZ) soils contained significantly more carbon at the topsoil and $32 \mathrm{~cm}$ depths but significantly less carbon at
$72 \mathrm{~cm}$. Carbon values at these depths, however, differed in regards to season (Table 1).

Both crab faecal pellets and burrow entrance soils had higher carbon concentrations than adjacent surface soils. Crab faecal pellets contained about three times more carbon ( $7.3 \pm 0.01 \% ; \mathrm{n}=4$ samples) than excavated soils. Excavated soils collected from ten burrow entrances had significantly higher carbon content than surface $\mathrm{CZ}$ soils collected during the same day from within $100 \mathrm{~m}$ (excavate piles $=2.3 \pm 0.2 \%$; crabzone $=1.6 \pm 0.01 \%$; Independent $\mathrm{t}=3$, df $=20, \mathrm{P}<0.01)$. The hypothesized pattern of organic carbon content of surface soils decreasing with distance from the burrow entrance was not found for five burrows sampled.

Soil samples were collected from 12 burrow chambers excavated in July 1995 that averaged $( \pm \mathrm{SD}) 49.3 \pm 12 \mathrm{~cm}$ deep. Chamber soils had an average $( \pm \mathrm{SE}$ ) organic carbon content of $1.6 \pm 0.2 \%$ which was approximately $60 \%$ higher than the depth-specific values predicted by a regression of carbon vs. soil depth (paired $\mathrm{t}=4, \mathrm{df}=11, \mathrm{p}<0.001)$. Chamber values were similar to surface soil values found immediately above ( $p>0.95$; Fig. 1 ) supporting the hypothesis that crabs contribute to subterranean pockets of elevated carbon content.

Root distribution: Vertical root profiles taken from the adjacent zones all indicated greater densities at the surface soils than below. The CZ had relatively lower root densities in the top $15 \mathrm{~cm}$ of soil than the nearby CLZ.

TABLE 1

Comparisons of organic carbon contents (\%) in soils sampled from the crab-and crabless zones

$\begin{array}{lcccc} & \text { Season } & \text { Crabless zone } & \text { Crab zone } & \text { Independent t-test } \\ 0-15 \mathrm{~cm} & \text { dry } & 2.4 \pm 0.3 & 1.8 \pm 0.1 & \mathrm{p}<0.02 \\ & \text { wet } & 2.2 \pm 0.2 & 1.5 \pm 0.1 & \mathrm{p}<0.02 \\ 32 \mathrm{~cm} & \text { dry } & 1.1 \pm 0.1 & 1.2 \pm 0.1 & \mathrm{~ns} \\ & \text { wet } & 0.8 \pm 0.1 & 0.02 \pm 0.04 & \mathrm{p}<0.0001 \\ 72 \mathrm{~cm} & \text { dry } & 0.45 \pm 0.1 & 0.8 \pm 0.1 & \mathrm{p}<0.005 \\ & \text { wet } & 0.15 \pm 0.03 & 0.22 \pm 0.02 & \mathrm{~ns}\end{array}$




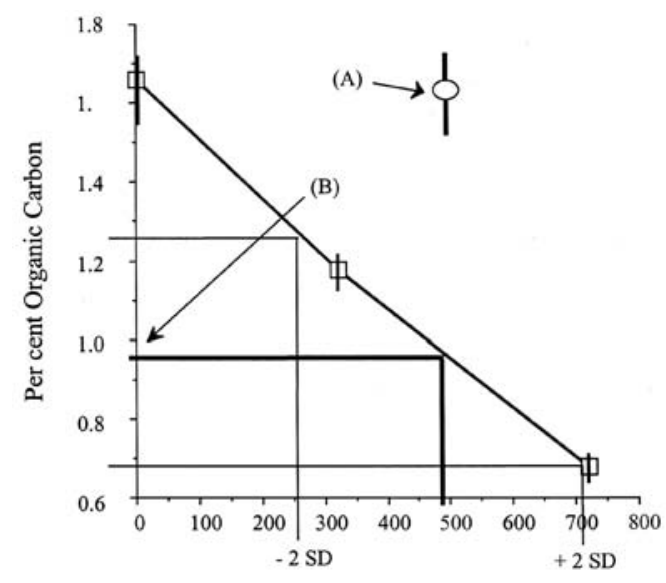

Sampling Depth from Surface ( $\mathrm{mm})$

Fig. 1. Actual (A) and predicted (B) organic carbon contents of soil collected from 12 excavated burrow chambers. Predictions of chamber carbon content are made against the regression of organic carbon content $( \pm 1 \mathrm{SD})$ as a function of depth in crabzone soils unassociated with burrows. The average ( $\pm 2 \mathrm{SD})$ burrow depth $(494 \pm 258 \mathrm{~mm})$ is plotted against the curve to develop a hypothetical predictive range for chamber soil carbon content versus chamber depth. Data show that burrow chambers contain significantly higher organic carbon than predicted by depth alone and statistically similar carbon content compared to surface values.

Surface densities of very fine and fine roots were $50 \%$ and $72 \%$ lower in the $\mathrm{CZ}$ than the CLZ respectively. In contrast, CZ soils, from 75 to $100 \mathrm{~cm}$ supported twice to four-times the

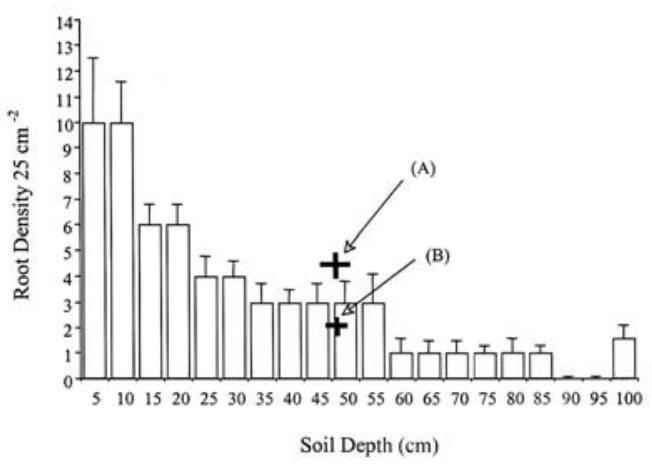

Fig. 2. Bars represent the average ( \pm SE) densities of very fine roots sampled in $25 \mathrm{~cm}^{2}$ increments from 11 pits dug during June - August, 1995 in the crabzone. (A) is the average root densities from 15 excavated burrow chambers. The crossbar represents the 11 chamber depths. (B) is the average root densities of the paired samples (depth-specific) from pit data. The crossbar represents the depth of paired samples from the pits. Statistical analysis reveals higher root densities in crab burrow chambers than expected by depth alone.

root densities than the CLZ but these differences were not statistically significant due to high variation relative to sample size (Table 2).

Burrow chambers had higher root densities than did same-depth soils within the CZ unassociated with chambers. Chambers had $4.5 \pm$ $0.8 \mathrm{~m}^{-2}$ roots vs. $2.3 \pm 0.325 \mathrm{~m}^{-2}$ (Paired $\mathrm{t}=$ $2.8, \mathrm{df}=14, \mathrm{p}=0.01$; Fig. 2).

TABLE 2

Comparisons of densities of very fine and fine roots sampled from the surface and from between 75 and $100 \mathrm{~cm}$ deep from the crab and crabless zones. Insignificant differences for the deeper soils likely result from high variation about the means

Crabzone

$\begin{array}{llr}0-15 \mathrm{~cm} & \text { Very Fine Roots } & 26.6 \pm 4.6(\mathrm{n}=11) \\ & \text { Fine Roots } & 0.7 \pm 0.2(\mathrm{n}=11) \\ 75-100 \mathrm{~cm} & \text { Very Fine Roots } & 0.84 \pm 0.4(\mathrm{n}=5) \\ & \text { Fine Roots } & 0.16 \pm 0.1(\mathrm{n}=5)\end{array}$

Crabless zone

$$
\begin{gathered}
53 \pm 6.6(\mathrm{n}=4) \\
2.5 \pm 0.5(\mathrm{n}=4) \\
0.16 \pm 0.4(\mathrm{n}=5) \\
0.08 \pm 0.06(\mathrm{n}=5)
\end{gathered}
$$

Independent t-test

$$
\begin{gathered}
\mathrm{p}<0.02 \\
\mathrm{p}<<0.001
\end{gathered}
$$

ns

ns

Data are averages \pm SE, organized by sampling depth and season. Crabzone samples are gathered from the control treatment quadrangles from the randomized block design for the time period specific to the sampling period from the crabless zone samples. Quadrangle data represent the averages of two samples taken from randomly selected subplots. Sample sizes are small and therefore provide only a preliminary assessment. The crabless zone was sampled with 6 and 4 independent profiles collected during the dry and wet seasons respectively. The crabzone was sampled from control quadrangles of the exclosure experiment using 10 independent profiles for the two seasons. 
Crab exclusion experiment: Average crab densities among the 15 quadrangles at the beginning of the exclosure experiment (baseline) did not differ statistically from one another $(\mathrm{F}=0.3, \mathrm{df}=2, \mathrm{p}=0.75)$ and averaged $( \pm \mathrm{SD})$ $17.3 \pm 7.4$ crabs $25 \mathrm{~m}^{-2}$ (ranging from 6 to 32 burrows $25 \mathrm{~m}^{-2}$ ). Burrow densities were experimentally and significantly reduced in exclosures to $3.9 \pm 0.6$ compared to control densities averaging $17.3 \pm 3.5$ over the two-year study $(\mathrm{F}=4.6, \mathrm{df}=2, \mathrm{p}=0.01)$. Additional results related to baseline and maintenance conditions of the experimental setup are published elsewhere (Sherman 2002, 2003).

Few biologically significant differences in organic carbon content were found for the data collected at the beginning (baseline) or end of the two-y experiment for any depth (Figs. 3 a-c). A significant baseline blocking effect was detected for surface soils $(\mathrm{F}=6, \mathrm{df}=4,8$, $\mathrm{P}=0.014$ ) indicating normal spatial variation initially found within forest floor litter accumulations and soil chemistry. A significant effect was also found for baseline soils sampled from $72 \mathrm{~cm}$ among randomly-assigned treatments indicating that fenced-control quadrangles began the experiment with higher carbon $(\mathrm{F}=$ $19 \mathrm{df}=2,8 ; \mathrm{p}=0.001)$.

Surface soils: After two y of crab exclusion, average $( \pm \mathrm{SE})$ percent organic carbon of surface soils sampled from exclosures increased from a baseline value of $2 \pm 0.2$ to 2.3 $\pm 0.3(15.7 \%)$ but this increase was statistically insignificant. Final exclosure values for surface soils were $22 \%$ higher than the pooled control values (Fig. 3a). In this case, Models I and II repeated-measures ANOVAs present different output. While model II finds this betweensubjects treatment difference to be statistically significant $(\mathrm{F}=4, \mathrm{df}=2 / 32, \mathrm{p}<0.03)$, Model I does not. Model I does, however, detect the tendency of a potential blocking effect suggesting the continuation of spatial variation in surface carbon concentrations $(\mathrm{F}=4, \mathrm{df}=4 / 8$, $\mathrm{p}=0.052)$. Neither model detects a significant effect of time (within-subjects) either alone or in interaction.

32 and $72 \mathrm{~cm}$ soils: No statistically significant or graphically meaningful patterns emerged over the 2-y study for soils sampled from either $32 \mathrm{~cm}$ or $72 \mathrm{~cm}$ depths regardless of model of ANOVA used (Figs. 3 b,c).
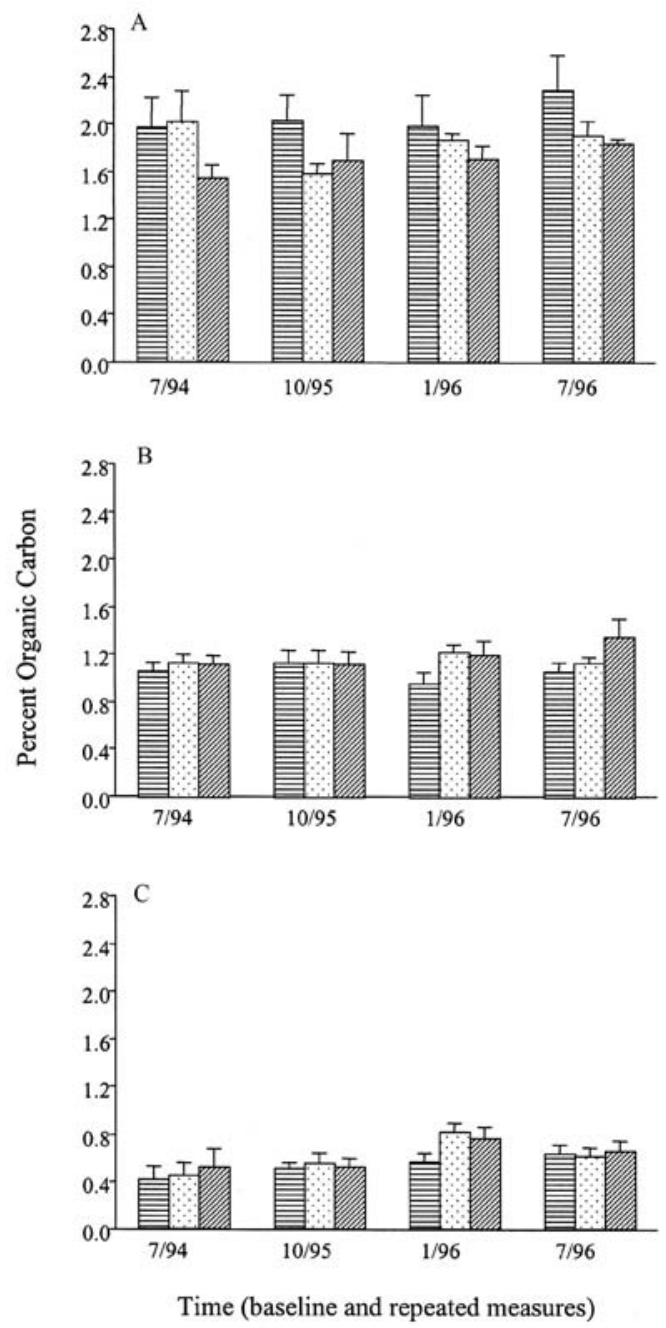

Fig. 3. a-c. Treatment effects of experimental crab exlosure experiment. Mean $( \pm \mathrm{SE})$ per cent organic carbon as a function of treatment and time at three depths sampled: (a) surface, (b) $32 \mathrm{~cm}$, (c) $72 \mathrm{~cm}$. Baseline data were gathered in July, 1994. Fenced-exclosures are horizontal striped, open control are spotted, fenced-control are diagonal striped. 


\section{DISCUSSION}

It is easier to describe than explain the bi-zonal sampling data of soil and root distributions. First, the crabless zone contains higher concentrations of both organic carbon and root densities in its top soils than does the crabzone. This pattern extends to at least $32 \mathrm{~cm}$ during the wet season when nutrients can leach downwards and roots are actively foraging. Significantly higher litter accumulations in the crabless zone (Sherman 2003) could partially explain this pattern that is representative of many tropical rain forest soil profiles elsewhere (Stark and Jordan 1976, Jordan 1985, Terborgh 1992). Second, both organic carbon content and root densities decrease with soil depth in both zones. Significantly higher organic carbon in soils of $72 \mathrm{~cm}$ in the crabzone during the dry season might reflect the absence of rains that might otherwise passively leach nutrients downwards from the litter that collects during these months in both zones. Alternatively, if there is a dry-season die-back of fine roots, resulting decomposition might lead to higher carbon contents in these lower soils. In the crabzone, however, the crabs maintain a continuous (albeit sharply reduced) activity through the dry season and likely relocate small quantities of litter from the surface to their chambers about $0.5 \mathrm{~m}$ below. Distributions of root densities reflect carbon stores. While decreases in carbon with depth were pronounced for all profiles from both zones, profiles in the crabzone were less steep due in part to elevated levels of surface carbon in the crabless zone. Root density profiles also differed markedly between the zones where the crabless zone's dense root mat dropped off steeply after $15 \mathrm{~cm}$ and the crabzone supported relatively higher root densities deeper down.

These generally descriptive, yet preliminary, findings about the larger study site have two possible explanations: (a) a biotic, active mechanism involving land crabs that forage for surface litter relocating it to their burrow chambers and (b) an abiotic, passive mechanism that recognizes how the soils that define, in part, the two adjacent zones may differentially affect litter decomposition, nutrient cycling dynamics and subsequently root distributions. Because the differential substrate hypothesis $\left(\mathrm{H}_{\mathrm{b}}\right)$ lies beyond the scope of this study, I will focus much of the remaining analysis on the potential mechanistic role crabs may play in this ecosystem-level dynamic. A rigorous test contrasting these two hypotheses, however, is warranted.

Experimental data gathered from crab exclosures established within the crabzone (de facto crabless zones), reveal unambiguous increases in litter accumulation on the soil surface over two years (Sherman 2003). Similar findings exist from studies of other forest types supporting other crab taxa and, therefore, do not come as a surprise (Robertson 1986, O'Dowd and Lake 1989, Robertson and Daniel 1989, Kellman and Delfosse 1993, Micheli 1993, McIvor and Smith 1995, Twilley et al. 1997, Green et al. 1999). By relocating much of the litter layer to their subterranean burrow chambers (Sherman 2003), data presented here provide mixed evidence that such litter relocation and handling by G. quadratus may additionally lead to reductions in nutrient and, thereby, root concentrations within the top soils while increasing these concentrations in deeper soils. It is also possible that burrowing activity, itself, also directly influences soil nutrient distributions (sensu Smith et al. 1991) although data testing this were not gathered here.

In this study, I hypothesized that exclosures would accumulate leaves on the surface and the resulting organic carbon profile would be made steeper, relative to control treatments, as more litter decomposed on the surface while less was transported by crabs below ground. After two $y$ of exclusion, the surface soils provided ambivalent results (Model I ANOVA revealed only significant blocking effects while Model II ANOVA revealed significant treatment effects). Such ambivalence may indicate a problem more with design used than the hypothesis tested. First, I assume that two y represent sufficient time to test for changing surface carbon values; data may reveal a developing rather than mature trend. Second, 
five replicates per treatment (with two point samples per quadrangle per sampling period) may inadequately address spatial variation expected in a functioning primary rain forest. Third, exclosures responded to predatory release from crabs in many ways: Exclosures, relative to control replicates, accumulated over two y (a) a conspicuous litter layer (Sherman 2003) with associated humus formation, (b) increased fungal colonization, (c) a $144 \%$ increase in seedling establishment (Sherman 2002), and (d) a developing root mat. Additionally, an invertebrate decomposer community (Sherman 1997) colonized the nascent resource patch within the exclosures. All of these processes might serve to reduce carbon concentrations as biomass develops before reaching a steady state. Were we to control for these other responses to predatory release from crabs, we might find much higher carbon values in exclosures than we do.

Deeper soil samples, collected from the experimental quadrangles at 32 and $72 \mathrm{~cm}$, were less obviously affected by experimental crab exclusion. In fact, no significant findings were made from the repeated-measures analyses for these depths. I had initially considered two opposing predictions whereby an experimental decrease in crab activity might lead to deeper soils with either (a). more nutrients (e.g., the leaching down of nutrients from an accumulating litter layer on the surface), or (b.) less nutrients (e.g., the cessation of both burrow construction and litter relocation). Given the conceptual plausibility of both an increase and decrease, the neutral results from 32 and $72 \mathrm{~cm}$ were unexpected. The significant dryseason increase in carbon content at $72 \mathrm{~cm}$ for fenced-control quadrangles sample tells us little because there is no similar increase in the open-control treatment. These findings also contrast with those from the bi-zonal sampling where the crabless zone acted as a de facto exclosure. Higher crabless zone values for 32 $\mathrm{cm}$ during the wet season and lower values at $72 \mathrm{~cm}$ during the dry season may indicate differences in nutrient movement through the two distinct substrates or reveal a time factor as experimental exclosures lasted only two years.
Alternatively, a sampling problem may be at play. Additional horizontal sampling might have clarified the results (more profile replicates), however, standard errors throughout the study tended to be small. Vertically, the depths of 32 and $72 \mathrm{~cm}$, chosen specifically to straddle burrow depth, may have missed their mark. Burrow depths were variable, ranging from $15 \mathrm{~cm}$ to $150 \mathrm{~cm}(\mathrm{n}=44$; Sherman 1997). Excluding a single $150 \mathrm{~cm}$ outlier, $25 \%$ of the distribution of burrow depths was more shallow than $36 \mathrm{~cm}$ depth, $50 \%$ were between 37 and $56 \mathrm{~cm}$, and the final $25 \%$ were between 58 and $69 \mathrm{~cm}$. What we can conclude from the randomized block design is that we did not find a continuous layer of subterranean carbon elevation at the 32 or $72 \mathrm{~cm}$ depths.

After initiating both my sampling protocol and the exclosure experiment, I reconsidered my search for organic carbon in continuous subterranean layers and chose instead to focus my sampling effort on the burrow chambers themselves. Data from this more focused search supports the hypothesis that crabs and their foraging/burrowing behavior can increase carbon stores: chamber soils were significantly higher than one would predict for same-depth, nearby soils unassociated with burrows and indistinguishable in their carbon content from surface soils. As hypothesized, I also measured a significant root proliferation presumably responding to these pockets of high nutrient content.

The degree to which nutrients can accumulate at the chamber, however, can be increased by leaf litter storage, crab defecation, throughflow from the surface following the burrow's path to the chamber, or the turnover of the roots themselves. In contrast, some of these carbon vectors might be reduced through routine cleanings that crabs do almost nightly during the wet season. I am aware of only a few studies that address, in passing, this topic (e.g., Lee 1997) and I did not gather data on this. After a crab cleans its burrow of litter, loose soils and faecal pellets, one can easily find the debris in and nearby the excavate piles always located at the burrow's mouth. It is possible, therefore, that crabs relocate ultimately less carbon below 
ground than might otherwise be expected. Yet, sampling from surface soils (and excavate) surrounding the burrow opening for carbon content, revealed neither elevated carbon in the excavate soils nor the hypothesized gradual decrease with distance from the mouth. It is plausible, therefore, that the primary effect of land crabs on nutrient dynamics may be more modest than previously suggested: perhaps they merely hasten rates of litter break-down of surface litter with the secondary effect of creating isolated subterranean pockets of elevated nutrient content at the chambers.

I argue that we now have sufficient data to propose a general mechanism describing the potential role for crabs in coastal rain forest systems. Crabs forage selectively for seedlings (Delfosse 1990, O’Dowd and Lake 1990, Green et al. 1997, Sherman 2002, Lindquist 2004); fruits and seeds (Lee 1985, 1988, Garcia-Franco et al. 1991, O'Dowd and Lake 1991, Capistrán-Barradas, P. Moreno, O. Defeo, pers. com. 2002, Lindquist 2004) and leaves (O'Dowd and Lake 1989, Kellman and Delfosse 1993, Green et al. 1999, Sherman 2003) on the soil surface within about $10 \mathrm{~m}$ of their burrow entrances (Sherman 1997). They selectively relocate leaves of a certain species and condition to their burrow chambers (Sherman 2003) that range from about 0.25 to one $\mathrm{m}$ below ground (average $0.5 \mathrm{~m}$; Sherman 1997). Collectively, crabs may remove a majority of the accumulating leaf litter layer in the crabzone (Sherman 2003). Because generally, crabs do not fully consume the leaves, they accumulate within the chambers (O'Dowd and Lake 1989, Sherman 2003) and begin to decompose. By burying the leaves (sensu Beare et al. 1992, Hanlon 1982), or by tearing them into smaller pieces (Camilleri 1992, Micheli 1993), crabs likely increase rates of decomposition above those accomplished by microbes and microfauna alone (Kavanagh and Kellman 1992). Crabs, thereby, create pockets of high nutrient concentrations in soils adjacent to their chambers that attract foraging roots of nearby plants. Crab burrows, which remain active for several months or more (Green 1993, Sherman 1997), can attract roots over extended periods. Nutrient richness of these chamber pockets may increase through root turnover or respiration or decrease if faecal pellets of crabs ultimately remain on the surface.

Our general understanding of the mechanism by which crab-moderated litter accumulation alters distributions of organic carbon and/or roots remains inconclusive. Few studies have addressed this issue for any crab system (land or mangrove). Furthermore, findings presented here represent only half the story because the alternative and possibly parsimonious hypothesis suggesting an effect of differing substrates on distributions of both crabs and carbon/roots has not yet been tested. Sandy soils, for example, are generally unable to support long residence times for humus and organic carbon because sand grains are a poor substrate to which the labile compounds that comprise young humus can bind (Ladd et al. 1985). Sandy rain forest soils are also known to lack the substantial root mass more generally associated with rain forest clays (Jordon 1985, Scott et al. 1992, Terborgh 1992). Richer forest soils often produce more leaf litter than poorer soils (Jordon 1985) offering further possible explanations for the differential litter accumulations. However, greater leaf litter production may be off-set by higher decomposer activity also known to correlate with richer soils (Lavelle et al. 1985). Additionally, the clay substrate and associated root mat represent a difficult burrowing option for crabs and those that live in the narrow transition zone clearly prefer patches of sandier substrate. The confounding of the two variables, soil substrate and crab density, confuses our efforts to differentiate between the abiotic and biotic (crab) explanations of the findings. While the experimental exclosures established within the crabzone did allow me to preliminarily address the substrate issue by artificially creating replicated regions of 'crabless zone' within the crabzone, further sampling and experimentation will be required to tease these two confounding mechanisms apart.

Clearly, further field experimentation is required to tease apart the two mechanisms. Until then, we should prudently recognize that 
human-based threats to the land crab population dynamics might well generate unintended effects related to changing floristic diversity and nutrient cycling.

\section{ACKNOWLEDGMENTS}

I thank David Allan, Gary Fowler, Barb Smuts, Earl Werner and Donald Zak for improving the original dissertation. Mariana Altrichter, Martin Kellman and four anonymous reviewers improved subsequent drafts. The work would have been impossible without the following field assistants: Ted Lee, Mark George, Dario Primo, Ben Gillette, David Walther, Leslie Patton, Andy Stubblefield, Adam Ringia, Michael Ebinger, Patryce Avsharian, Bret Freeman and field trouble shooters: Larry Gilbert, Paulino Valverde. I performed soil chemistry work in the soils laboratory of the University of Michigan under the supervision of Diana Randlett and Donald Zak. Joy Bergelson assisted with statistical issues.

Without the gracious permission of the Osa Conservation Area (ACOSA), I could not have worked on their lands. This work was funded by the National Science Foundation Dissertation Improvement Grant \# 033703, Charles A. and Anne M. Lindbergh Foundation-Harry Frank Guggenheim Fellowship, Hewlett Foundation, Organization for Tropical Studies, University of Michigan's Rackham Pre-Doctoral Fellowship, Rackham Dissertation and Discretionary Grants, School of Natural Resources and Environment, and Latin American and Caribbean Studies Program.

\section{RESUMEN}

El cangrejo Gecarcinus quadratus (Gecarcinidae) habita madrigueras terrestres y afecta el retorno de carbón orgánico a los suelos de los bosques lluviosos al reducir la acumulación de hojarasca y alterar su proceso de descomposición. En el Parque Nacional Corcovado en Costa Rica, G. quadratus vive en altas densidades (de 1-6 cangrejos $\mathrm{m}^{-2}$ ) en una franja boscosa que se extiende desde la costa del Océano Pacífico hasta $600 \mathrm{~m}$ tierra adentro. En esta región de bosque costero ('zona cangrejera'), los cangrejos buscan alimento selectivamente en la hojarasca, trasladando lo que recolectan a sus cuevas de más de $1 \mathrm{~m}$ de profundidad. Comparaciones entre la superficie de los suelos de la zona cangrejera y los de la región inmediata pero más lejana a la costa y sin cangrejos ('zona no-cangrejera'), revelan que la capa superficial del suelo (a $10 \mathrm{~cm}$ ) en la zona cangrejera contiene $39 \%$ menos carbono orgánico, $72 \%$ menos raíces finas y $50 \%$ menos raíces muy finas. Estos resultados contrastan con muestreos similares realizados en ambas zonas en suelos de 75-100 cm de profundidad, donde se encontraron similares concentraciones de carbono orgánico, pero la zona cangrejera tenía el doble de raíces finas y más del cuádruple de raíces muy finas que en la zona no-cangrejera. Encierros experimentales de $25 \mathrm{~m}^{2}$ realizados durante 2 a no revelaron ningún efecto de manipulación en los perfiles verticales de carbono orgánico. Sin embargo, los suelos superficiales de los encierros presentaron $18 \pm 8 \%$ más carbono que los valores de control. En contraste, excavaciones en los agujeros de los cangrejos de un promedio $( \pm \mathrm{SD}$ ) de profundidad de 48 \pm 12 centímetros revelaron concentraciones subterráneas elevadas $(+60 \%)$ de carbono orgánico con densidades elevadas de raíces finas $(+1500 \%)$ y de raíces muy finas $(+200 \%)$, en relación con muestras tomadas a la misma profundidad en la zona cangrejera (pero no asociadas a cuevas de cangrejos).

Palabras clave: Costero, Parque Nacional Corcovado, Costa Rica, distribución, Gecarcinidae, Gecarcinus quadratus, cangrejo terrestre, hojarasca, bosque lluvioso neotropical, nutrimento, carbón orgánico, planta, raíces, comunidad.

\section{REFERENCES}

Aшson, L.E. 1965. Organic Carbon. p. 1367-1378. In C.A. Black, F.E., Clark, R.C., Dinauer, D.D., Evans, L.E., Ensminger \& J.L. White (eds.). Methods of Soil Analysis Part 2: Chemical and Microbiological Properties. No. 9 in the Agronomy Series. Am. Soc. Agro., Milwakee, Wisconsin.

Anderson, J.M. \& M.J. Swift. 1983. Decomposition in tropical forests. p. 287-310. In S.L. Sutton, T.C. Whitmore \& A.C. Chadwick (eds.). Tropical rain forest: ecology and management. Special Publication Series No. 2 of the British Ecological Society. Blackwell, Oxford, England.

Anderson, J.M., J. Proctor \& H.W. Vallack. 1983. Ecological studies in four contrasting lowland rain forests in Gunung Mulu National Park, Sarawak. J. Ecol. 71: 503-527.

Beare, M.H., R.W. Parmelee, P.F. Hendrix \& W. Cheng. 1992. Microbial and faunal interactions and effects 
on litter nitrogen and decomposition in agroecosystems. Ecol. Mono. 62(4): 569-591.

Bernhard, F. 1970. Étude de la litiére et de sa contribution au cycle des élements mineraux en foret ombrophile de basse Cote d'Ivoire. Oecol. Plantarium 7: 279-300.

Burggren, W. \& R. McMahon. 1988. Biology of the land crabs. Cambridge University, Cambridge, England.

Camilleri, J.C. 1992. Leaf-litter processing by invertebrates in a mangrove forest in Queensland. Mar. Biol. (Berlin) 114(1): 139-145.

Delfosse, B. 1990. The effect of the red land crab, Gecarcinus lateralis, on the litter layer, nutrient availability and seedling recruitment in a semi-deciduous seasonal dry tropical forest. Msc. Thesis, York University, Toronto, Ontario, Canada. 199 pp.

Emmerson, W.D. \& L.E. McGwynne. 1992. Feeding and assimilation of mangrove leaves by the crab Sesarma meinerti de Man in relation to leaf-litter production in Mgazana, a warm-temperate southern African mangrove swamp. J. Exp. Mar. Biol. \& Ecol. 157: 41-53.

Facelli, J.M. \& S.T.A. Pickett. 1991a. Plant litter: Its dynamics and effects on plant community structure. Bot. Rev. 57(1): 2-32.

Facelli, J.M. \& S.T.A. Pickett. 1991b. Indirect effects of litter on woody seedlings subject to herb competition. Oikos 62(2): 129-138.

Garcia-Franco, J.G., V. Rico-Gray \& O. Zayas. 1991. Seed and seedling predation of Bromelia penquin L. by the red land crab Gecarcinus lateralis Frem. in Veracruz, Mexico. Biotropica 23: 96-97.

Green, P.T. 1993. The role of the red land crabs (Gecarcoidea natalis Pocock 1888; Brachyura, Gecardinidae)in structuring rain forest on Christmas Island, Indian Ocean. Ph.D. thesis, Monash University, Melbourne, Australia.

Green, P.T. 1997. Red crabs in rain forest on Christmas Island, Indian Ocean: activity patterns, density and biomass. J. Trop. Biol. 13: 17-38.

Green, P., D. O’Dowd, \& S. Lake. 1997. Control of seedling recruitment by land crabs in a rain forest on a remote oceanic island. Ecology 78: 2474-2486.

Green, P.T., D. O’Dowd \& S. Lake, 1999. Monopolization of litter processing by a dominant land crab on a tropical oceanic island. Oecologia 119: 435-444.

Haines, B.L. 1978. Element and energy flows through colonies of the leaf-cutting ant Atta colombica, in Panama. Biotropica 10(4): 270-277.
Hanlon, A. 1982. The breakdown and decomposition of alochthonous and autochthonous plant litter in an oligotrophic lake. Hydrobiologia 88: 281-288.

Jordan, C.F. 1985. Nutrient cycling in Tropical Forest Ecosystems: Principles and their application in conservation and management. Wiley, Chichester, United Kingdom. p. 179.

Kavanagh, T. \& M. Kellman. 1992. Seasonal patterns of fine root proliferation in a tropical dry forest. Biotropica 24:157-165.

Kellman, M. \& B. Delfosse. 1993. Effect of the red land crab (Gecarcinus lateralis) on the leaf-litter in a tropical dry forest in Veracruz, Mexico. J. Trop. Ecol. 9: 55-65.

Kwok, P.W. \& S.Y. Lee. 1995. The growth performances of two mangrove crabs, Chiromanthes bidens and Parasesarma plicata under different leaf-litter diets. Hydrobiologia 295): 141-148.

Ladd, J.N., M. Amato \& J.M. Oades. 1985. Decomposition of plant material in Australian soils III. Residual organic and microbial biomass carbon and nitrogen from isotope-labeled legume material and soil organic matter decomposing under field conditions. Austral. J. Soil Res. 23(4): 603-612.

Lavelle, P., E., Blanchart, A. Martin, S. Martin, A. Spain, F. Toutain, I. Barois \& R. Schaefer. 1993. A hierarchical model for decomposition in terrestrial ecosystems: Applications to soils of the humid tropics. Biotropica 25: 130-150.

Lavelle, P. 1997. Faunal activities and soil processes: Adaptive strategies that determine ecosystem function. Pp. 93-132. In M. Begon \& A.H.Fitter (eds.). Advances in Ecological Research Vol. 27. Academic, New York, New York, USA.

Lee, M. 1985. The dispersal of Pandamus tectorius by the land crab Cardisoma carnifex. Oikos 45: 169-173.

Lee, M. 1988. Food preferences and feeding behavior of the land crab Cardisoma carnifex. Micronesica 21: 274-279.

Lee, S.Y. 1997. Potential trophic importance of the faecal material of the mangrove sesarmine crab Sasarma messa. Mar. Ecol. Progr. Ser. 159: 279-284.

Lindquist, E.S. \& R.C. Carroll. 2004. Differential seed and seedling predation by crabs: impacts on tropical coastal forest composition. Oecologia 141: 661-671.

Lugo, A.E., E.G. Farnworth, D. Pool, P. Jerez \& G. Kaufman. 1973. The impact of the leaf cutter ant Atta columbica on the energy flow of a tropical wet forest. Ecology 54: 1292-1301. 
McIvor, C.C. \& T.J. Smith III. 1995. Differences in the crab fauna of mangrove areas at a southwest Florida and a northeast Australian location: Implications for leaflitter processing. Estuaries 18: 591-597.

Micheli, F. 1993. Feeding ecology of mangrove crabs in North Eastern Australia: mangrove litter consumption by Sesarma messa and Sesarma smithii. J. Exp. Mar. Biol. Ecol. 171: 165-186.

Molofsky, J. \& C.K. Augspurger. 1992. The effect of leaflitter on early seedling establishment in a tropical forest. Ecology 73: 68-77.

Newman, J.A., J. Bergelson, \& A. Grafen. 1997. Blocking factors and hypothesis tests in ecology: is your statistics text wrong? Ecology 78: 1312-1320.

Norden, U. 1994. Leaf litterfall concentrations and fluxes of elements in deciduous tree species. Scand. J. For. Res. 9: 9-16.

O’Dowd, D.J. \& P.S. Lake. 1989. Red crabs in rain forest, Christmas Island: removal and relocation of leaf fall. J. Trop. Ecol. 5: 337-348.

O’Dowd, D. \& S. Lake. 1990. Red crabs in rain forest, Christmas Island: differential herbivory of seedlings. Oikos 58: 289-292.

O’Dowd, D \& S. Lake. 1991. Red crabs in rain forest, Christmas Island: removal and fate of fruits and seeds. J. Trop. Ecol. 7: 113-122.

Pinder, A.W. \& A.W. Smits. 1993. The burrow microhabitat of the land crab Cardisoma guanhumi: Respiratory/ ionic conditions and physiological responses of crabs to hypercapnia. Phys. Zool. 66: 216-236.

Proctor, J. 1983. Tropical forest litterfall. I. Problems of data comparison. In Sutton, S.L., T.C. Whitmore \& A.C. Chadwick. (eds.). Tropical rain forest: ecology and management. Special Publication No. 2 of the British Ecological Society. Blackwell, Oxford, England.

Proctor, J. 1984. Tropical forest litterfall II. The data set. pp. 83-115. In A.C. Chadwick \& S.L., Sutton (eds.).Tropical rain forest: The Leeds Symposium, Blackwell, Oxford, England.

Proctor, J. 1984. Tropical forest litterfall II. The data set. In Tropical rain forest: ecology and management. A.C. Chadwick \& S.L. Sutton (eds.) (Supplementary Volume). Proc. Leeds Philo. \& Lit. Soc.
Robertson, A.I. 1986. Leaf-burying crabs: their influence on energy flow and export from mixed mangrove forests (Rhizophora spp.) in northeastern Australia. J. Exp. Mar. Biol. \& Ecol. 102: 237-248.

Robertson, A.I. \& P.A. Daniel. 1989. The influence of crabs on litter processing in high intertidal mangrove forests in tropical Australia. Oecologia 78: 191-198.

Scott, D.A., J. Proctor \& J. Thompson. 1992. Ecological studies on a lowland evergreen rain forest on Maracá Island, Roraima, Brazil. II. Litter and nutrient cycling. J. Ecol. 80: 705-717.

Sherman, P.M. 1997. Direct and indirect effects of the land crab Gecarcinus quadratus (Gecarcinidae) on seedling density, organic carbon distributions and rooting profiles in Corcovado National Park, Costa Rica. Ph.D. thesis. University of Michigan, Ann Arbour, Michigan, USA.

Sherman, P.M. 2002. Effects of land crabs on seedling densities and distributions in a mainland neotropical rain forest. J. Trop. Ecol. 18: 67-89.

Sherman, P.M. 2003. Effects of land crabs on leaf litter distributions and accumulations in a mainland tropical rain forest. Biotropica 35: 365-374.

Smith, T.J., K.G. Boto, S.D. Frusher \& R.L. Giddins. 1991. Keystone species and mangrove forest dynamics: the influence of burrowing by crabs on soil nutrient status and forest productivity. Estuarine, Coastal \& Shelf Sci. 33: 419-432.

Stark, N.M. \& C.F. Jordan, 1978. Nutrient retention by the root mat of an Amazonian rain forest. Ecology 59: 434-437.

Terborgh, J. 1992. Diversity and the tropical rain forest. Scientific American Library, New York, New York, USA. p. 242.

Turkay, M. 1973. Bermerkungen zu elnigen Landkrabben (Crustacea, Decapoda). Bull. Mus. Nat. Hist. Paris 142: 969-980.

Twilley, R.R., M. Pozo, V.H. Garcia, V.H. Rivera-Monroy, R. Zambrano, \& A. Bodero. 1997. Litter dynamics in riverine mangrove forests in the Guayas River estuary, Equador. Oecologia (Berlin) 111: 109-112.

Vitousek, P.M. \& R.L., Jr. Sanford. 1986. Nutrient cycling in moist tropical forest. An. Rev. Ecol. Syst. 17: 137-167. 
